\title{
Jejunogastric intussusception: An unusual cause of hematemesis
}

\author{
Inian Samarasam MS FRCS ${ }^{1}$, Sudhakar Chandran B MS ${ }^{1}$, Uday Shankar DNB ${ }^{1}$, Biju George DM², \\ Ashok Chacko DM², George Mathew MS MD ${ }^{1}$
}

I Samarasam, S Chandran B, U Shankar, B George, A Chacko, G Mathew. Jejunogastric intussusception: An unusual cause of hematemesis. Can J Gastroenterol 2005;19(12):735-736.

Jejunogastric intussusception is an uncommon but potentially lifethreatening complication of a previous gastrojejunal anastamosis. Although jejunogastric intussusception was first described in 1914, fewer than 200 cases have been reported in the English literature thus far. Awareness of this rare complication would help in early diagnosis and appropriate management. Described here is a case report of a patient who presented with hematemesis due to an acute jejunogastric intussusception associated with gangrene of the intussuscepted jejunum.

\section{L'invagination jéjunogastrique : Une cause inhabituelle d'hématémèse}

L'invagination jéjunogastrique est une complication peu courante d'anastomose gastrojéjunale pouvant mettre en jeu le pronostic vital. Bien que l'invagination jéjunogastrique ait été décrite pour la première fois en 1914, moins de 200 cas ont été déclarés jusqu’à présent dans les publications de langue anglaise. La sensibilisation à cette complication rare contribuerait à un diagnostic précoce et à une prise en charge pertinente. Est décrit aux présentes le cas d'un patient qui a consulté en raison d'une hématémèse causée par une invagination jéjunogastrique aiguë associée à une gangrène du jéjunum invaginé.

Key Words: Gastric surgery; Hematemesis; Jejunogastric intussusception; Late complication

\section{CASE PRESENTATION}

A 57-year-old man presented to the emergency department with a three-day history of worsening upper abdominal pain. He had two episodes of large volume hematemesis just before his presentation. He also gave a history of having an abdominal operation for peptic ulcer disease nine years prior, the details of which were not available.

On examination, he was dehydrated but hemodynamically stable. Abdominal examination revealed minimal tenderness in the epigastric region with no evidence of generalized peritonitis. Blood investigations revealed a hemoglobin of $102 \mathrm{~g} / \mathrm{L}$. The white cell count, serum electrolytes and renal function were within normal limits. Blood gas analysis showed a mild metabolic acidosis. The plain $\mathrm{x}$-rays of the abdomen revealed an abnormal homogeneous density in the left upper quadrant. An urgent esophagogastroduodenoscopy was performed, which showed large amounts of altered blood and a blackish intraluminal mass in the stomach.

An emergency laparotomy was performed. At operation, the stomach was dilated with an intraluminal soft tissue mass. The previous retrocolic gastrojejunostomy was noted, along with intussusception of the efferent loop of the anastamosis. A gastrotomy was performed, which revealed intussuscepted loops of jejunum with full-thickness gangrene (Figures 1 and 2). The intussusception was reduced, the gastrojejunostomy was taken down, and a small-bowel resection and anastamosis was performed. Because there was no evidence of previous vagotomy, nor any evidence of scarring of the pylorus due to peptic ulcer disease, a further drainage procedure was not performed. The patient had an uneventful postoperative recovery and was discharged on day 12 .

\section{DISCUSSION}

Jejunogastric intussusception was first reported by Bozzi (1) in 1914 in a patient who had undergone a gastrojejunostomy. Lundberg (2) reported this complication following a Billroth II gastrectomy. Subsequently, jejunogastric intussusception has been reported in almost all types of gastric surgery that involve the creation of an anastamosis between the stomach and the jejunum.

There have been reports of the occurrence of this problem, from as early as six days to as late as 20 years following a gastrojejunal anastamosis (3).

Three anatomical types of jejunogastric intussusception have been described by Shackman (4): afferent loop intussusception (16\%); efferent loop intussusception (74\%); and intussusception involving both loops (10\%).

The etiology of jejunogastric intussusception is still unclear. The most widely accepted theory is disordered motility with functional hyperperistalsis triggered by spasm or hyperacidity (5). Mechanical predisposing factors include adhesions, a long mesentery and a sudden increase in abdominal pressure.

Jejunogastric intussusception can present in an acute or chronic form. The classical triad of acute jejunogastric

${ }^{1}$ Department of Surgery; ${ }^{2}$ Department of Gastroenterology, Christian Medical College and Hospital, Vellore, Tamilnadu, India

Correspondence: Dr Inian Samarasam, Department of General Surgery, Christian Medical College Hospital, Vellore 632 004, Tamilnadu, India.

Telephone +91-416-2282079, fax +91-416-223-2035 or 223-2103, e-mail inians@cmcvellore.ac.in

Received for publication August 6, 2005. Accepted September 15, 2005 


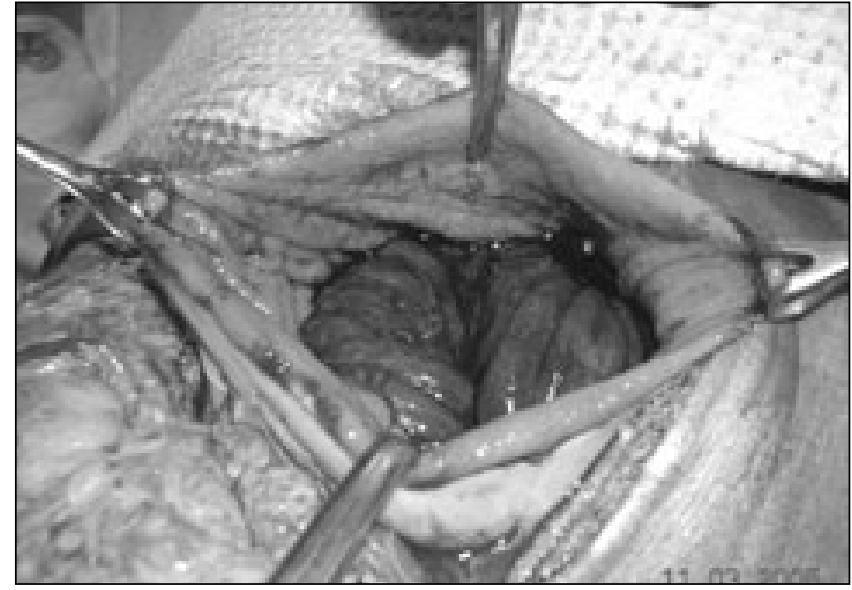

Figure 1) A view of the intussuscepted loops of jejunum on opening the stomach

intussusception includes sudden onset of epigastric pain, vomiting with or without hematemesis and a palpable epigastric mass in a patient who has undergone previous gastric surgery (6). The chronic form may present with symptoms similar to the acute form, but the symptoms may be milder and transient and may subside spontaneously.

A plain $\mathrm{x}$-ray of the abdomen may show a homogeneous density in the left upper quadrant that represents small bowel in the stomach (7). Upper abdominal contrast series also confirms the diagnosis showing a 'coil spring' jejunalfilling defect in the stomach produced by barium between the edematous folds (8) (Figure 2). Endoscopy, performed by someone familiar with this rare entity, will certainly be diagnostic.

The treatment of the acute variety of jejunogastric intussusception is prompt surgery. At operation, if the intussuscepted jejunum is viable and reducible, then simple reduction is performed. To prevent recurrence, the reduced jejunum is fixed to either the afferent limb of the gastrojejunal anastamosis or the transverse mesocolon. If the bowel is nonviable it must be resected, as in this patient. The treatment of the chronic recurrent variety of jejunogastric intussusception is symptomatic. If symptoms persist then revisional surgery may have to be performed.

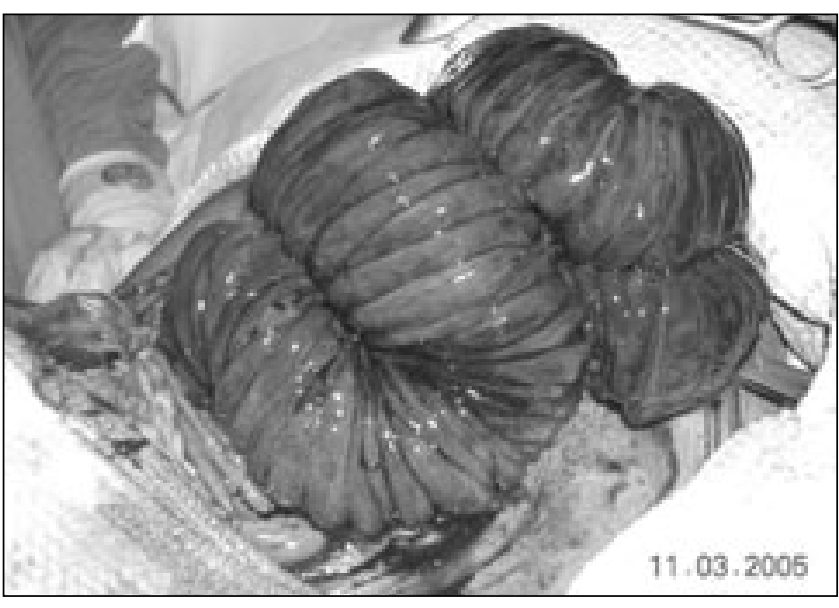

Figure 2) The 'coil spring' appearance of the gangrenous, jejunal loops inside the stomach, due to jejunogastric intussusception

\section{CONCLUSION}

Jejunogastric intussusception is a very rare complication of gastrojejunal anastamosis. When a patient who has had a gastrojejunal anastamosis presents with hematemesis, melena or upper abdominal pain, the possibility of a jejunogastric intussusception should be considered along with more common diagnoses such as a stomal ulcer. Because this entity is not frequently encountered, awareness of this rare complication is essential to recognize this condition during endoscopy and to treat this problem effectively by operation.

\section{REFERENCES}

1. Bozzi E. Annotation. Bull Acad Med 1914;122:3-4.

2. Lundberg S. Retrograde Dunndarminvagination nach Gastroenterostomie. Acta Chir Scand 1922;54:423-33

3. Conklin EF, Markowitz AM. Intussusception, a complication of gastric surgery. Surgery 1965;57:480-8

4. Shackman R. Jejunogastric intussusception. Br J Surg 1940;27:475-80.

5. Robertson DS, Weder C. Acute jejunogastric intussusception. Can J Surg 1968;1:210-4.

6. Foster DG. Retrograde jejunogastric intussusception; a rare cause of hematemesis; review of the literature and report of two cases. AMA Arch Surg 1956;73:1009-17.

7. Caudell ES, Lee CM Jr. Acute and chronic jejunogastric intussusception. N Engl J Med 1955;253:635-40.

8. Devor D, Passaro E Jr. Jejunogastric intussusception: Review of four cases - diagnosis and management. Ann Surg 1966;163:93-6. 


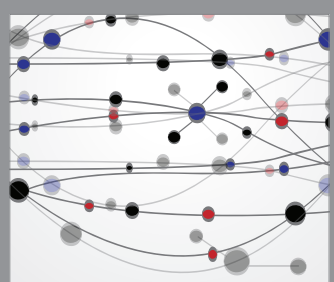

The Scientific World Journal
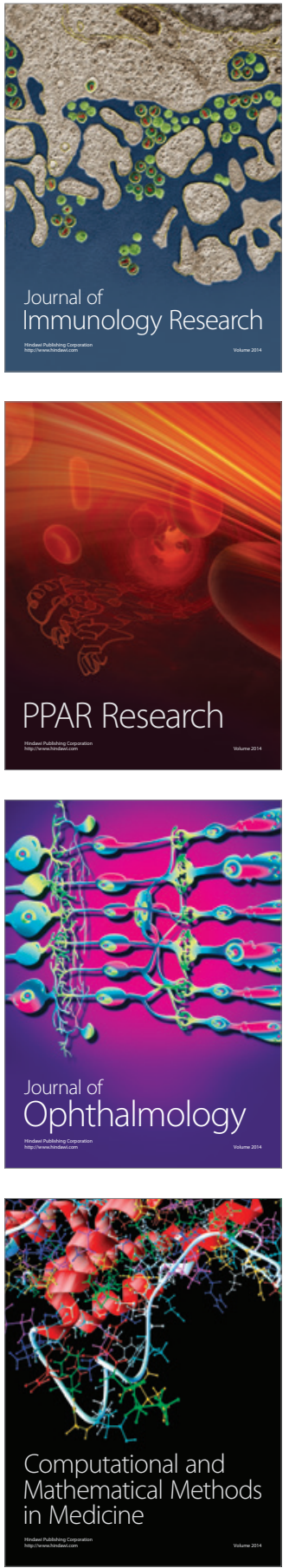

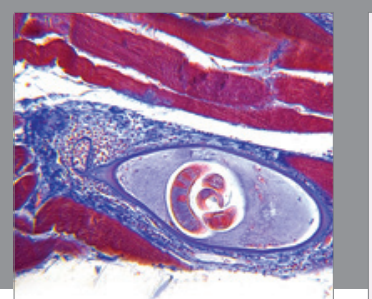

Gastroenterology Research and Practice

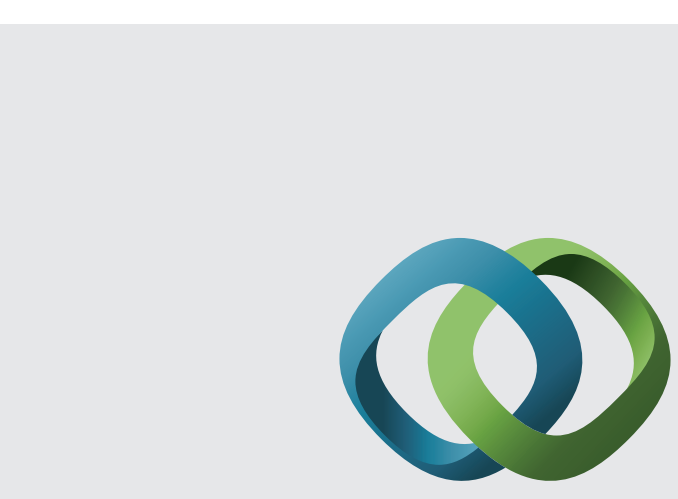

\section{Hindawi}

Submit your manuscripts at

http://www.hindawi.com
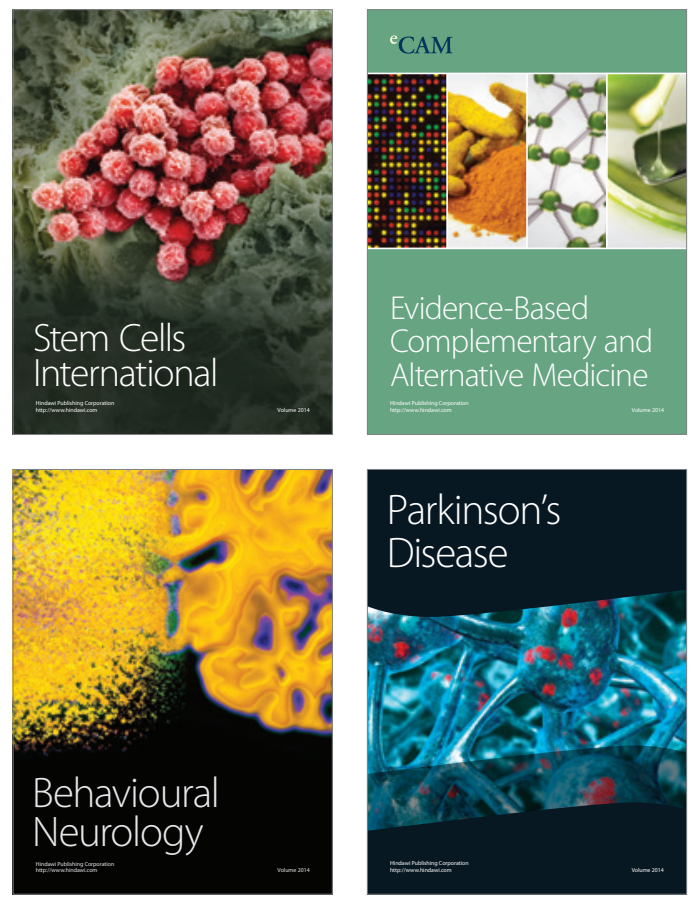
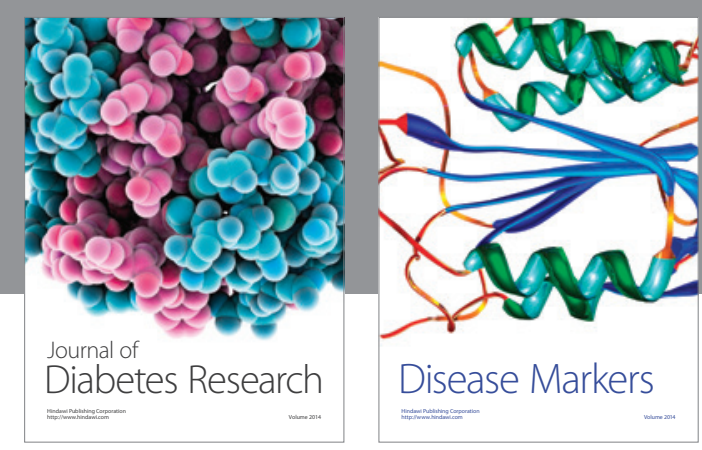

Disease Markers
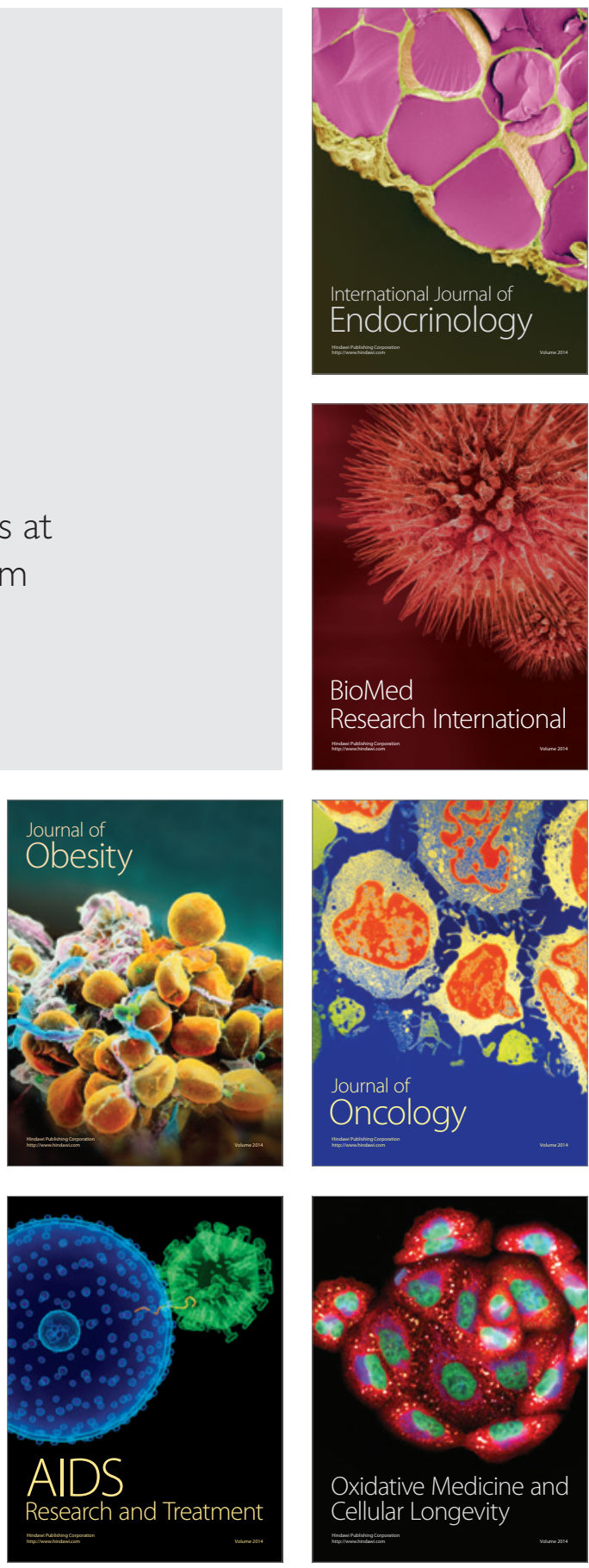